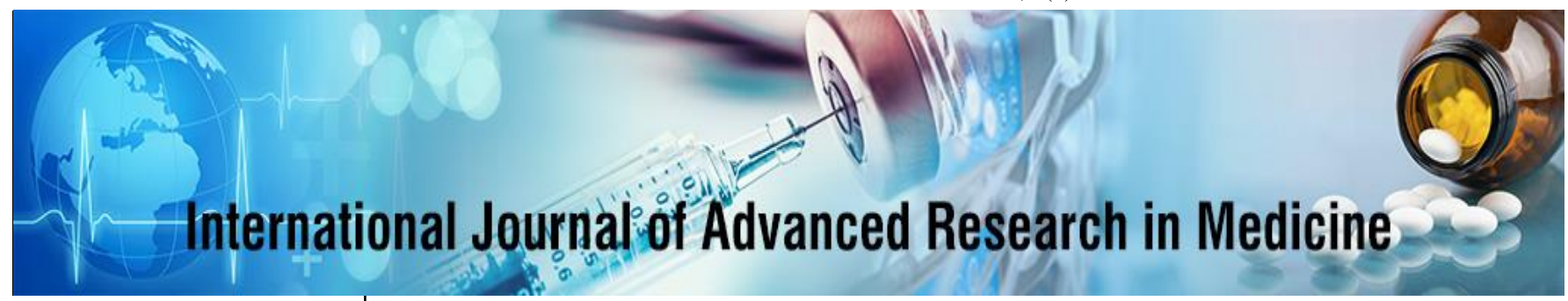

E-ISSN: 2706-9575

P-ISSN: 2706-9567

IJARM 2021; 3(1): 381-385

Received: 02-11-2020

Accepted: 05-12-2020

Dr. Tauqeer Anjum Mir Senior Resident, Department of Anesthiology and Critical

Care, Sher-i-Kashmir Institute of Medical Sciences, Srinagar, India

Dr Rohan Roshan Nayak Assistant professor in Dept of Anaesthesiology, IMS and SUM Hospital, Bhubaneswar, India

Dr. Hemesh Shewale International Training Fellow, Kings College, London, England
Corresponding Author: Dr. Hemesh Shewale International Training Fellow, Kings College, London England

\section{Analysis of Dexmedetomidine added to Ropivacaine in Supraclavicular Brachial Plexus block}

\author{
Dr. Tauqeer Anjum Mir, Dr Rohan Roshan Nayak and Dr. Hemesh \\ Shewale
}

DOI: https://doi.org/10.22271/27069567.2021.v3.i1g.165

\begin{abstract}
Aim: To evaluate the effect of Dexmedetomidine added to Ropivacaine in Supraclavicular Brachial Plexus block.

Material and Methods: This study was performed in the Department of Anaesthesia, Mahatma Gandhi Missions Institute of Health Sciences, Navi Mumbai, Maharashtra after approval by the Institute Ethics Committee. After getting written informed consent from patients, this study was carried out as a controlled, randomized (chit method), double blind, prospective study in 60 patients. Sensory and motor blockade of radial, median, musculocutaneous and ulnar nerves were recorded at regular intervals (at each min till complete blockade) after drug injection. Following observations were noted intra and post operatively. The duration of analgesia or first request for analgesic defined as the time to attain a Visual Analogue Score (VAS) of 4 or $>4$ after Ropivacaine administration. The VAS was recorded post-operatively every $30 \mathrm{~min}$ till the score of 4 or $>4$.
\end{abstract}

Results: Duration of sensory block was significantly longer in group RD as compared to group R ( $<$ < 0.001). It was found that duration of motor block increased more with Dexmedetomidine addition $(407.33 \pm 53.09 \mathrm{~min})$ than with Ropivacaine alone $(278.66 \pm 44.77 \mathrm{~min})$. There was significant increase in duration of analgesia in group RD $(685.33 \pm 90.02 \mathrm{~min})$ than with group R $(344.00 \pm 52.06 \mathrm{~min})$. In RD group 2 patients developed haematoma and only 1 patient develop blood in aspiration due to arterial puncture, and in $\mathrm{R}$ group 1 patient develop haematoma and 2 patients developed blood in aspiration.

Conclusion: We conclude that Dexmedetomidine is a good adjuvant in supraclavicular brachial plexus block for upper limb surgeries.

Keywords: Surgery, Upper Limb, VAS, Dexmedetomidine, Ropivacaine, Supraclavicular brachial Plexus block

\section{Introduction}

The use of peripheral nerve block for orthopaedic surgery has increased rapidly during the last few decades, with increasing demand for post operative pain relief, early \& efficient rehabilitation, with reduced morbidity and mortality ${ }^{[1]}$. Acute postoperative pain is the result of complex physiological reactions. The dorsal horn ${ }^{[2]}$ is the site of terminations of primary afferents and there is a complex interaction between such fibres, intrinsic spinal neurons, descending modulatory pain fibres and various neurotransmitters such as Serotonin, Norepinephrine, Acetylcholine, Adenosine and Glutamate ${ }^{[3]}$.

Supraclavicular brachial plexus block is safe, time efficient, cost effective technique that provides satisfactory surgical condition like complete motor \& sensory block ${ }^{[4]}$. Supraclavicular brachial plexus block is blocked at the level of distal trunk/division where it has tightest formation that provides rapid and dense anesthesia.

Besides all local anaesthetics Bupivacaine ${ }^{[5]}$ is more frequently used, because of its higher potency and prolonged duration of action. One of the disadvantages is its cardiotoxicity, especially with inadvertent injection into Subclavian Artery. A long acting local anaesthetic drug, Ropivacaine ${ }^{[6]}$ was approved for clinical use in 1996.

Ropivacaine is an amino-amide local anaesthetic (LA) effective for both intraoperative anaesthesia and post-operative analgesia. For peripheral nerve blockade, Ropivacaine is comparable to Bupivacaine and Levobupivacaine ${ }^{[7]}$. However, the lower lipid solubility of Ropivacaine gives greater sensory and motor differential blockade and reduces the potential for CNS and cardiotoxicity. 
Many techniques are used to improve the quality of brachial plexus block like adding an adjuvant, use of ultra sound guided block ${ }^{[8]}$ or insertion of a catheter ${ }^{[9]}$. In comparison to single-shot block the insertion of peripheral nerve catheter is more time consuming, more painful, costly, and has higher complication rate (eg. infection) and needs more post-operative care ${ }^{[1]}$.

In order to avoid catheter complications, adding an adjuvant would be our choice for prolonging the duration of nerve block. There had always been a constant search for adjuvant drug to the regional nerve block that prolong the duration of analgesia with lesser adverse effects. The search for the ideal additive continues, and led us to try for faster onset, denser block and for prolonging the duration of peripheral nerve blockade.

Alpha-2-adrenergic [10] agonists were chosen for their sedative, analgesic, antihypertensive and antiemetic properties along with decreased requirement of local anaesthetic drugs. Clonidine ${ }^{[11]}$ a partial alpha-2 agonist has been shown to prolong the duration of anaesthesia and analgesia in peripheral nerve blocks.

Dexmedetomidine [12] a selective alpha-2 agonist, with affinity eight times that of clonidine, also has been shown to prolong the sensory and motor duration when added as an adjuvant to local anaesthetic in peripheral nerve block. Thus it is worthy to evaluate the effect of addition of Dexmedetomidine.

\section{Material and Method}

This study was performed in the Department of Anaesthesia, Mahatma Gandhi Missions Institute of Health Sciences, Navi Mumbai, Maharashtra after approval by the Institute Ethics Committee from 2015 to 2017. After written informed consent from patients, this study was carried out as a controlled, randomized (chit method), double blind, prospective study in 60 patients. Subjects having ASA Grade I \& II and age between 21-60 years were included in the study. Patients allergic to the drugs used in the study, having neuromuscular disorder, history of hypertension, hepatorenal and metabolic disease, bleeding disorders, patient on anticoagulants, pregnancy, lactational mother and having local site infection were excluded from the study.

On the day prior to surgery, a thorough clinical examination of the patient was performed including general physical examination and systemic examination. All patients were explained about the anaesthesia technique and written informed consent was taken. Patients were kept NBM for 68 hours prior to surgery. Routine investigations were done (Hb\%, BT, CT, Urine Analysis, LFT, RFT, Chest X-ray, ECG) along with specific investigations required pertaining to the procedure and patient.

60 patients of ASA grade I \& II were randomly divided into 2 groups of 30 patients each. Before the procedure, visual analogue scale (VAS) on $0-10 \mathrm{~cm}$ was explained to the patient for the assessment of pain where 0 denotes no pain and 10 denotes worst pain.

\begin{tabular}{|c|c|c|}
\hline Groups & Drugs \& Doses & No. of Patients \\
\hline I (R) & $0.75 \%$ Ropivacaine $29 \mathrm{ml}+1 \mathrm{ml} \mathrm{NS}$ & 30 \\
\hline II (RD) & $0.75 \%$ Ropivacaine $29 \mathrm{ml}+1 \mu \mathrm{g} / \mathrm{kg}$ of Dexmedetomidine with $1 \mathrm{ml}$ N.S & 30 \\
\hline
\end{tabular}

The supraclavicular block was performed after appropriate patient positioning in supine position with the head turned to the opposite side and arm placed medially towards the body with strict aseptic precautions. Midclavicular point, external jugular vein and subclavian artery pulsation were identified. About $2 \mathrm{~cm}$ above the midclavicular point just lateral to subclavian artery pulsation, a 24 gauge, 1.5 inches short beveled needle was introduced and directed caudal and medially until paraesthesia was encountered, when $29 \mathrm{ml}$ of $0.75 \%$ ropivacaine with either of $1 \mathrm{ml}$ saline or adjuvant was injected in this area and ruling out intravascular injection intermittently by frequent aspiration. A 3 min massage was performed to facilitate an even drug distribution.

Sensory and motor blockade of radial, median, musculocutaneous and ulnar nerves were recorded at regular intervals (at each min till complete blockade) after drug injection. Following observations were noted intra and post operatively.

Sensory block was assessed by the pin prick method at every 1 minute after completion of drug injection in the dermatomal areas corresponding to median nerve, radial nerve, ulnar nerve and musculocutaneous nerve till complete sensory blockade. Sensory onset was considered when there was a dull sensation to pin prick with a needle along the distribution of any of the above-mentioned nerves. Complete sensory block was considered when there was complete loss of sensation to pin prick.

Duration of sensory block was defined as the time interval between the end of Ropivacaine administration and the complete resolution of anesthesia on all nerves. Sensory block was graded as:
- Grade 0: Sharp pin felt

- Grade 1: Analgesia, dull sensation felt

- Grade 2: Anaesthesia, no sensation felt.

Motor block was assessed at each 1 minute till complete motor blockade after drug injection. Onset of motor blockade was considered when there is Grade 1 motor blockade. Peak motor block was considered when there is Grade 2 motor blockade.

Duration of motor block was defined as the time interval between the end of Ropivacaine administration and the recovery of complete motor function of the hand and forearm. Motor block was determined according to a modified Bromage scale for upper extremities on a 3-point scale.

- 0 - normal motor function with full extension and flexion of elbow, wrist, and fingers

- 1 - decreased motor strength, with ability to move only fingers

- 2 - complete motor block with inability to move elbow, wrist, and fingers

The duration of analgesia or first request for analgesic defined as the time to attain a Visual Analogue Score (VAS) of 4 or $>4$ after Ropivacaine administration. The VAS was recorded post-operatively every $30 \mathrm{~min}$ till the score of 4 or $>4$. The rescue analgesia was given in the form of Inj. Paracetamol $15 \mathrm{mg} / \mathrm{kg} \mathrm{IV}$ at the visual analogue scale $\geq 4$ and the time of administration were noted.

The sensory and motor responses was assessed every $30 \mathrm{~min}$ after surgery until they attain preoperative state. Pain was assessed by VAS every $30 \mathrm{~min}$, and when the VAS 4 or $>4$, 
the patient received Inj. Paracetamol as rescue analgesic and the study was discontinued.

\section{Statistical analysis}

The obtained data were tabulated and analyzed using unpaired student T-test. Results were expressed as mean \pm standard deviation. T- test was applied for onset and duration of sensory and motor blockade and duration of analgesia, and hemodynamic parameters. SPSS software was used for statistical analysis of observed parameters. P value $<0.05$ was considered statistically significant.

\section{Results}

Majority of patients were male i.e. $80 \%$ and $86 \%$ in group $\mathrm{R}$ and group $\mathrm{RD}$ respectively. In both groups, most of the patients belonged to age group of 21-30 years (56\% and $53 \%$ in the group R and RD respectively). The mean age in $\mathrm{R}$ and $\mathrm{RD}$ groups was $32.36+8.55$ and $31.16+7.44$ years respectively.

Onset of sensory block that was earlier in group RD $(9.53 \pm 2.65)$ than group $\mathrm{R}(13.6 \pm 2.47)$ and the difference was statistically significant $(\mathrm{p}<0.05)$. Motor block in group $\mathrm{R}$ and group $\mathrm{RD}$ which was $19.43 \pm 3.95 \mathrm{~min}$ and $11.46 \pm 2.98$ min respectively and the onset of motor block was earlier in group $\mathrm{RD}$, the difference was statistically highly significant $(\mathrm{p}<0.001)$ as shown in Table 1 .

Table 1: Onset of sensory and motor block

\begin{tabular}{|c|c|c|c|c|}
\hline \multirow{2}{*}{ Time interval (min): Sensory Block } & \multicolumn{2}{|c|}{ Group R (n=30) } & \multicolumn{2}{c|}{ Group RD $(\mathbf{n}=\mathbf{3 0})$} \\
\cline { 2 - 5 } & No. & $\mathbf{\%}$ & No. & $\mathbf{\%}$ \\
\hline $1-5$ & 0 & 0 & 2 & 6.66 \\
\hline $6-10$ & 3 & 10 & 20 & 66.66 \\
\hline $11-15$ & 21 & 70 & 7 & 23.33 \\
\hline $16-20$ & 6 & 20 & 1 & 3 \\
\hline Mean (min) & 13.6 & & 9.53 & \\
\hline SD & \pm 2.47 & & \pm 2.65 & \\
\hline $1-5$ & & & & \\
\hline Time interval (min): Motor Block & 1 & 3.33 & 1 & 3.33 \\
\hline $11-15$ & 3 & 10 & 10 & 33.33 \\
\hline $16-20$ & 14 & 46.66 & 16 & 53.33 \\
\hline $21-25$ & 10 & 33.33 & 3 & 10 \\
\hline Mean (min) & 2 & 6.66 & 0 & 0 \\
\hline S.D. & 19.43 & & 11.46 & \\
\hline
\end{tabular}

Table 2 shows mean duration of sensory block that was $303.33 \pm 39.52 \mathrm{~min}$ and $441.66 \pm 74.07 \mathrm{~min}$ in group $\mathrm{R}$ and
RD respectively and the difference was statistically highly significant $(\mathrm{p}<0.001)$.

Table 2: Duration of sensory and motor block

\begin{tabular}{|c|c|c|c|c|}
\hline \multirow{2}{*}{ Time interval (min): Sensory Block } & \multicolumn{2}{|c|}{ Group R (n=30) } & \multicolumn{2}{|c|}{ Group RD (n=30) } \\
\cline { 2 - 5 } & No. & $\mathbf{\%}$ & No. & $\mathbf{\%}$ \\
\hline $200-300$ & 16 & 53.33 & 3 & 10 \\
\hline $301-400$ & 12 & 40 & 5 & 16.66 \\
\hline $401-500$ & 2 & 6.66 & 15 & 50 \\
\hline $501-600$ & 0 & 0 & 7 & 23.33 \\
\hline Mean (min) & 303.33 & & 441.66 & \\
\hline S.D & \pm 39.52 & & \pm 74.07 & \\
\hline Time interval (min): Motor Block & & & & \\
\hline $301-300$ & 25 & 83.33 & 2 & 6.66 \\
\hline $401-600$ & 3 & 10 & 13 & 43.33 \\
\hline 501-600 & 2 & 6.66 & 13 & 43.33 \\
\hline Mean (min) & 0 & 0 & 2 & 6.66 \\
\hline S.D. & 278.66 & & 407.33 & \\
\hline
\end{tabular}

Table 3 depicts that mean duration of analgesia was $685.33 \pm 90.02 \mathrm{~min}$ in group RD which was more than mean duration of analgesia in group $\mathrm{R}(344 \pm 52.06 \mathrm{~min})$ and the difference was highly significant $(\mathrm{p}<0.001)$.

Table 3: Duration of analgesia

\begin{tabular}{|c|c|c|c|c|}
\hline \multirow{2}{*}{ Time interval (min) } & \multicolumn{2}{|c|}{ Group R (n=30) } & \multicolumn{2}{|c|}{ Group RD $(\mathbf{n}=\mathbf{3 0})$} \\
\cline { 2 - 5 } & No. & $\mathbf{\%}$ & No. & 0 \\
\hline $200-300$ & 9 & 30 & 0 & 10 \\
\hline $301-400$ & 18 & 60 & 1 & 10 \\
\hline $401-500$ & 2 & 20 & 1 & 10 \\
\hline $501-600$ & 1 & 10 & 15 & 50 \\
\hline $601-700$ & 0 & 0 & 12 & 20 \\
\hline $701-800$ & 0 & & 685.33 & \\
\hline Mean (min) & 344 & & 90.02 & \\
\hline S.D. & 52.06 & & & \\
\hline
\end{tabular}


As shown in Table 4, Pre block VAS score in RD \& R group was $5.13 \pm 1.49 \& 5.06 \pm 1.12$ respectively. Maximum reduction of mean VAS score in RD group occurred at 15 min which was $0.5 \pm 0.84$ while in $\mathrm{R}$ group maximum reduction occurred at $30 \mathrm{~min}$ which was $0.96 \pm 0.91$. On inter group comparison, basal VAS score was similar in both groups but after administration of block, decrease in VAS score was more in group $\mathrm{RD}$ as compared to group $\mathrm{R}$. The
VAS score remained significantly at low level in group RD as compared to group $\mathrm{R}$ till $600 \mathrm{~min}$ after the block \& difference was statistically significant $(\mathrm{P}<0.05)$. At $720 \mathrm{~min}$ mean VAS score in RD group was 2.96 which was less than in comparison to $\mathrm{R}$ group which was 3.00 but difference was not significant $(\mathrm{P}>0.05)$.

Table 4: VAS Score

\begin{tabular}{|c|c|c|c|c|}
\hline \multirow{2}{*}{ Time } & \multicolumn{2}{|c|}{ Group R } & \multicolumn{2}{|c|}{ Group RD } \\
\hline & Mean & SD & Mean & SD \\
\hline Pre block (Basal) & 5.06 & 1.12 & 5.13 & 1.49 \\
\hline \multicolumn{5}{|l|}{ Post block at } \\
\hline $5 \mathrm{~min}$ & 1.9 & 0.74 & 1.46 & 0.61 \\
\hline $10 \mathrm{~min}$ & 1.3 & 0.98 & 1.06 & 1.12 \\
\hline $15 \mathrm{~min}$ & 1 & 1 & 0.5 & 0.84 \\
\hline $30 \mathrm{~min}$ & 0.96 & 0.91 & 0.5 & 0.84 \\
\hline $60 \mathrm{~min}$ & 1.1 & 1.11 & 0.5 & 0.84 \\
\hline $120 \mathrm{~min}$ & 1.33 & 1.04 & 0.56 & 0.95 \\
\hline $180 \mathrm{~min}$ & 2.6 & 0.8 & 0.73 & 0.99 \\
\hline $240 \mathrm{~min}$ & 3.1 & 0.9 & 1 & 0.9 \\
\hline $300 \mathrm{~min}$ & 2.9 & 0.8 & 1.4 & 1.1 \\
\hline $360 \mathrm{~min}$ & 2.8 & 0.54 & 1.63 & 1.14 \\
\hline $480 \mathrm{~min}$ & 3.37 & 0.48 & 1.93 & 1.21 \\
\hline $600 \mathrm{~min}$ & 3.43 & 0.84 & 2.4 & 1.1 \\
\hline $720 \mathrm{~min}$ & 3 & 0.65 & 2.96 & 0.98 \\
\hline
\end{tabular}

Table 5 shows that there were no significant side effects during the study period. In RD group 2 patients developed haematoma and only 1 patient had blood on aspiration due to arterial puncture, and in $\mathrm{R}$ group 1 patient developed haematoma and 2 patients had blood on aspiration. No significant bradycardia and hypotension had been seen among both the groups. All the complications were managed by experienced anaesthesiologists according to standard protocols.

Table 5: Comparison of complications among the study groups

\begin{tabular}{|c|c|c|c|c|}
\hline \multirow{2}{*}{ Complications } & \multicolumn{2}{|c|}{ Group R } & \multicolumn{2}{c|}{ Group RD } \\
\cline { 2 - 5 } & No of patient (n=30) & Percentage & No of patients (n=30) & Percentage \\
\hline Haematoma & 1 & 3.33 & 2 & 6.66 \\
\hline Blood on aspiration & 2 & 6.66 & 1 & 3.33 \\
\hline Infection & 0 & 0 & 0 & 0 \\
\hline Bradycardia & 0 & 0 & 0 & 0 \\
\hline Hypotension & 0 & 0 & 0 & 0 \\
\hline Hypertension & 0 & 0 & 0 & 0 \\
\hline Allergic reactions & 0 & 0 & 0 & 0 \\
\hline Nausea & 0 & 0 & 0 & 0 \\
\hline Vomiting & 0 & 0 & 0 & 0 \\
\hline Others & 0 & 0 & 0 & 0 \\
\hline
\end{tabular}

\section{Discussion}

In this randomized double blind study, we evaluated the efficacy of Dexmedetomidine as an adjuvant to Ropivacaine in brachical plexus nerve block in term of onset of sensory and motor block, duration of sensory and motor block, duration of analgesia, sedation, haemodynamic variables, side effects \& complications (if any).

Our study showed onset of sensory block was faster in group RD than in group R, which was $13.60 \pm 2.47 \mathrm{~min}$ in group $\mathrm{R}$ while $9.53 \pm 2.65 \mathrm{~min}$ in group $\mathrm{RD}$ and the difference was statistically significant $(\mathrm{p}<0.05)$. These results coincide with the studies done by Nema et al. (2014) [13] where the onset was earlier in dexmedetomidine group and the result was statistically significant.

In our study onset of motor block in group $\mathrm{R}$ and $\mathrm{RD}$ group is $19.43 \pm 3.95 \mathrm{~min}$ and $11.46 \pm 2.98 \mathrm{~min}$. It was found that addition of Dexmedetomidine to Ropivacaine results in early onset of motor block and the difference was significant when compared statistically $(p<0.05)$. Our results matches with the studies done by Nema et al. (2014) ${ }^{[13]}$ where the onset was earlier in Dexmedetomidine group and the result was statistically significant.

Duration of sensory block in group $\mathrm{R}$ was $303.33 \pm 39.52$ $\mathrm{min}$ and $441.66 \pm 734.07 \mathrm{~min}$ in group RD. Duration of sensory block was significantly longer in group RD as compared to group $\mathrm{R}$ ( $\mathrm{p}<0.001)$. Results depicts that duration of sensory block is prolonged when Dexmedetomidine is added as an adjuvant. The result of our study are similar with Nema et al. (2014) ${ }^{[13]}$. Similar results of prolonged duration of sensory block with addition of Dexmedetomidine in brachial plexus block was found by Bharti et al. (2015) ${ }^{[14]}$, Santosh et al. (2016) ${ }^{[15]}$ and Vinit et al. (2017) ${ }^{[16]}$ in their studies. 
It was found that duration of motor block increased more with Dexmedetomidine addition $(407.33 \pm 53.09 \mathrm{~min})$ than with Ropivacaine alone $(278.66 \pm 44.77 \mathrm{~min})$ and the increase was highly significant $(\mathrm{p}<0.001)$ between group $\mathrm{R}$ and group RD. Similar result was also found in the study of Nema et al. (2014) ${ }^{[13]}$. Similar results of prolonged duration of motor block with addition of Dexmedetomidine in brachial plexus block was found by Bharti et al. (2015) ${ }^{[14]}$, Santosh et al. (2016) ${ }^{[15]}$ and vinit et al. (2017) ${ }^{[16]}$ in their studies.

In our study, there was significant increase in duration of analgesia in group RD $(685.33 \pm 90.02 \mathrm{~min})$ than with group $\mathrm{R}$ (344.00 $\pm 52.06 \mathrm{~min})$. The difference was highly significant $(\mathrm{p}<0.001)$. The result of our study are in accordance with Nema et al. (2014) ${ }^{[13]}$. Similar results of prolonged duration of analgesia with addition of Dexmedetomidine in brachial plexus block was found by Bharti et al. (2015) ${ }^{[14]}$, Santosh et al. (2016) ${ }^{[15]}$ and vinit et al. (2017) ${ }^{[16]}$ in their studies.

In our study, incidence of side effects were comparable $(P$ $>0.05$ ) in both the groups. In RD group 2 patients developed haematoma and only 1 patient develop blood in aspiration due to arterial puncture, and in $\mathrm{R}$ group 1 patient develop haematoma and 2 patients developed blood in aspiration. These can be minimized with experience of anaesthesiologist. Hypotension, bradycardia, respiratory depression, shivering and any other complications were not observed in any patient of either group.

Our results indicate that as an adjuvant, the side effect profile of Dexmedetomidine was quite favourable as none of the patient in RD group had profound deep sedation or respiratory depression and does not bring any additional morbidity to patients.

\section{Conclusion}

Dexmedetomidine $(1 \mu \mathrm{g} / \mathrm{kg})$ as adjuvant to Ropivacaine has faster onset, early and prolonged duration of sensory and motor blockade and increased duration of analgesia, without any significant side effects. So we conclude that Dexmedetomidine is a good adjuvant in supraclavicular brachial plexus block for upper limb surgeries.

\section{References}

1. Danninger T, Opperer M, Stavros G Memtsoudis. Perioperative pain control after total knee arthroplasty: An evidence based review of the role of peripheral nerve blocks. World J Orthop 2014;5(3):225-232.

2. Andrew $\mathbf{J}$ Todd. Neuronal circuitry for pain processing in the dorsal horn; Nat Rev Neuro Sci 2010;11(12):823-836.

3. Ciranna L. Serotonin as a Modulator of Glutamate- and GABA-Mediated Neurotransmission: Implications in Physiological Functions and in Pathology; Curr Neuropharmacol. 2006;4(2):101-114.

4. Pathak RG, Satkar AP, Khade RN. Supraclavicular brachial plexus block with and without Dexamethasone - A Comparative Study. Int J Sci Res Pub 2012;2(12):1-7.

5. Scott DB, Jebson PJR, Boyes RN. Pharmacokinetic study of the local anaesthetics bupivacaine (marcain) and etidocaine (duranest) in man $\mathrm{Br} J$ Anaesth 1973;45(10):1010-1012.
6. Kuthiala G, Chaudhary G. Ropivacaine: A review of its pharmacology and clinical use Indian $\mathbf{J}$ Anaesth 2011;55(2):104-110.

7. Kulkarni SB, Pimpare M, Govardhane BT. Comparison of levobupivacaine with ropivacaine for supraclavicular brachial plexus block. Int $J$ Res Med Sci 2016;4(9):3789-3796

8. Coventry DM. Ultrasound-guided brachial plexus blocks.British journal anaesthesia. Contin Educ Anaesth Crit Care Pain 2014;14(4):185-191.

9. Bowens C, Sripada R. Regional Blockade of the Shoulder: Approaches and Outcomes. Anesthesiology Res Prac 2012;2012:971963

10. Giovannitti JA, Thoms Sean M, Crawford JJ. Alpha-2 Adrenergic Receptor Agonists: A Review of Current Clinical Applications Anesth Prog 2015;62(1):31-38.

11. Limon-Boulez, Bouet-Alard R, Gettys TW, Lanier SM, Maltier JP, Legrand C. Partial agonist clonidine mediates alpha(2)-AR subtypes specific regulation of cAMP accumulation in adenylyl cyclase II transfected DDT1-MF2 cells; Mol Pharmacol 2001;59(2):331-8.

12. Brown HC, Mitchell DH, Silvius EN. Dexmedetomidine: a novel sedative-analgesic agent. Proc Bayl Univ Med Cent 2001;14(1):13-21.

13. Nema N, Badgaiyan H, Raskaran S, Kujur S, Vaskle P, Mujalde M. Effect of addition of dexmedetomidine to Ropivacaine hydrochloride $(0.75 \%)$ in brachial plexus block through supraclavicular route in upper limb surgeries: A clinical comparative study. J Evol Med Dent Sci 2014;3(55):12612-621.

14. Bharti N, Sardana DK, Bala I. The Analgesic Efficacy of Dexmedetomidine as an Adjunct to Local Anesthetics in Supraclavicular Brachial Plexus Block: A Randomized Controlled Trial. Anesth Analg 2015;121(6):1655-1660.

15. Singh AV, Singh S. Effects of Clonidine as an Adjuvant to Ropivacaine for Brachial Plexus Block via Axillary Approach International Journal of Interdisciplinary and Multidisciplinary Studies (IJIMS) 2015;2(5):45-50.

16. Khemka V, Jadeja PD. Comparative study of Ropivacaine with Dexmedetomidine versus Ropivacaine alone in supra clavicular brachical plexus block for upper limb surgery. Int $\mathbf{J}$ Sci Stud 2017;5(6):74-80. 